\title{
Зависимость морфологии поверхности ультратонких пленок висмута на слюдяной подложке от толщины пленки
}

\author{
(C) А.Н. Крушельницкий, Е.В. Демидов, Е.К. Иванова, Н.С. Каблукова, В.А. Комаров \\ Российский государственный педагогический университет им. А.И. Герцена, \\ 191186 Санкт-Петербург, Россия \\ ฯ E-mail: va-komar@yandex.ru
}

(Получена 27 декабря 2016 г. Принята к печати 12 января 2017 г.)

\begin{abstract}
Представлены результаты исследования поверхности пленок висмута толщинами 15-100 нм на слюдяной подложке методом атомно-силовой микроскопии. Установлен близкий к линейному характер зависимостей средней шероховатости поверхности и средней высоты фигуры роста от толщины пленки. Обнаружено увеличение среднего размера кристаллитов с увеличением толщины пленки, и выявлена слабая зависимость размера кристаллита от толщины при толщинах 27-70 нм.
\end{abstract}

DOI: 10.21883/FTP.2017.07.44641.27

\section{1. Введение}

К настоящему времени в литературе довольно детально описана структура поверхности пленок висмута на различных подложках [1-7]. Известно, что для поверхности пленок висмута характерны три типа структурных неоднородностей: 1) плоские фигуры роста треугольной формы (для пленок на слюде и стекле); 2) хиллоки (бугорки); 3) границы зерен (кристаллитов). Установлено, что вследствие малости толщины пленки ее поверхность существенным образом отражает объемную структуру, и, например, по анализу структуры поверхности пленок висмута можно определять размеры кристаллитов.

Систематические исследования [1,2] влияния режима получения и толщины пленки висмута на ее структуру проведены для пленок толщиной более 100 нм, полученных при высоких скоростях осаждения $\sim 50 \AA /$ с, т. е. в условиях, далеких от термодинамического равновесия. Указанное обстоятельство обусловливает актуальность проведенного исследования зависимости морфологии поверхности от толщины пленок, полученных на скоростях осаждения $\sim 1.5 \AA / \mathrm{c}$, в интервале толщин от 15 до $100 \mathrm{Hм}$.

\section{2. Методика эксперимента}

Пленки висмута были получены методом термического испарения в сверхвысоком вакууме $\sim 2 \cdot 10^{-8}$ мм рт.ст. на подложку из слюды (мусковит). Скорость осаждения материала на подложку $\sim 1.5 \AA / \mathrm{c}$, температура подложки $140^{\circ} \mathrm{C}$. После получения пленки подвергались отжигу при температуре $200^{\circ} \mathrm{C}$ в течение часа. Технологические параметры напыления образцов подбирались в соответствии с оптимальными режимами получения более толстых пленок - результаты работы [2]. Толщина образцов контролировалась кварцевым датчиком толщины.

Структура поверхности пленок изучалась методом атомно-силовой микроскопии (АСМ) с помощью скани- рующего зондового микроскопа Solver-P47Pro. Использовались зондовые датчики типа NSG01. Прибор калибровался по тестовым решеткам TGS1 фирмы NT-MDT. Эталон высоты, по паспортным данным, для решетки TGZ1 $-20.5 \pm 1.0$ нм, для TGZ2 $-104.5 \pm 2.0$ нм.

Дополнительно были рассчитаны размеры кристаллитов в полученных образцах. Описание метода расчета по готовому АСМ изображению поверхности пленки приведено в работах $[1,2,8]$. Кроме того, для более точного определения размеров кристаллитов пленка предварительно подвергалась химическому травлению в водном растворе смеси азотной и уксусной кислот.

\section{3. Экспериментальные результаты и их обсуждение}

Типичный микрорельеф поверхности ультратонких пленок висмута представлен на рис. 1. Установлено, что пленки имеют блочную структуру с преимуществен-

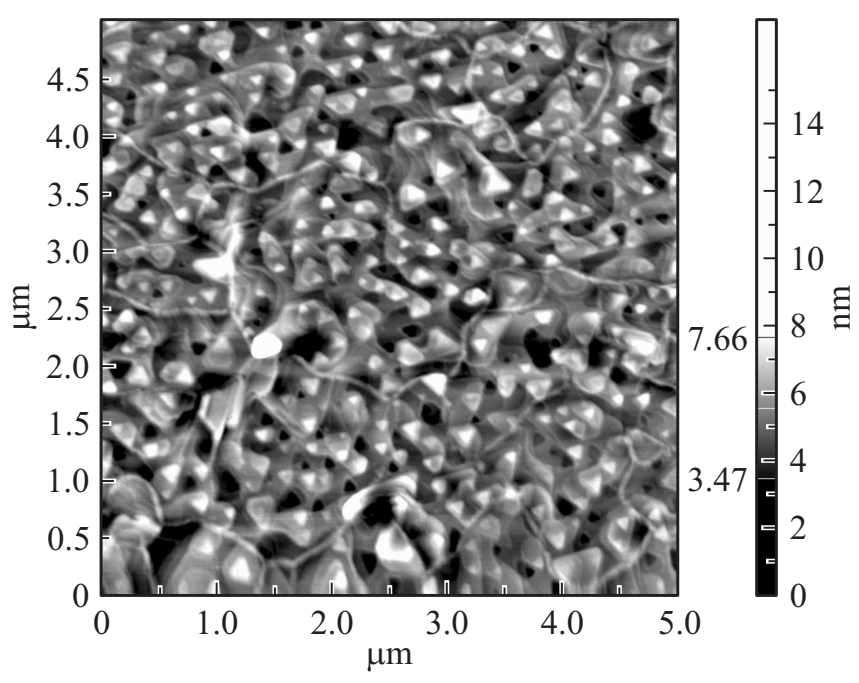

Рис. 1. АСМ изображение поверхности пленки висмута толщиной 40 нм. 
ной ориентацией тригональной оси $C_{3}$ перпендикулярно плоскости подложки. На поверхности пленок также наблюдаются три указанных выше типа структурных неоднородностей: фигуры роста, хиллоки, границы кристаллитов.

Фигуры роста и хиллоки полученных пленок отличаются от фигур роста и хиллоков пленок, полученных на высоких $\sim 50 \AA /$ с скоростях осаждения. Фигуры роста изменяют форму со слабо выступающей над поверхностью треугольной призмы на пирамидальную (трехгранная, иногда усеченная, пирамида) при повышении температуры подложки выше $100^{\circ} \mathrm{C}$. Хиллоки преимущественно имеют четкую огранку в виде выступающей над поверхностью треугольной (иногда шестиугольной) призмы.

Приобретение фигурами роста и хиллоками огранки свидетельствует о получении пленки в условиях, близких к термодинамическому равновесию [9] (подобные результаты также были получены другими авторами для пленок $\mathrm{W}$ и $\mathrm{Pd}[10]$ и $\operatorname{Ir}[11])$.

На рис. 2 представлены зависимости средней шероховатости поверхности пленок и средней высоты фигуры роста над ее основанием от толщины пленки. Графики хорошо аппроксимируются линейной зависимостью с коэффициентом детерминации $R^{2} \sim 0.8$.

Средняя шероховатость поверхности не превышает значения в $2 \%$ от толщины пленки. При этом возвышение фигуры роста над ее основанием зачастую
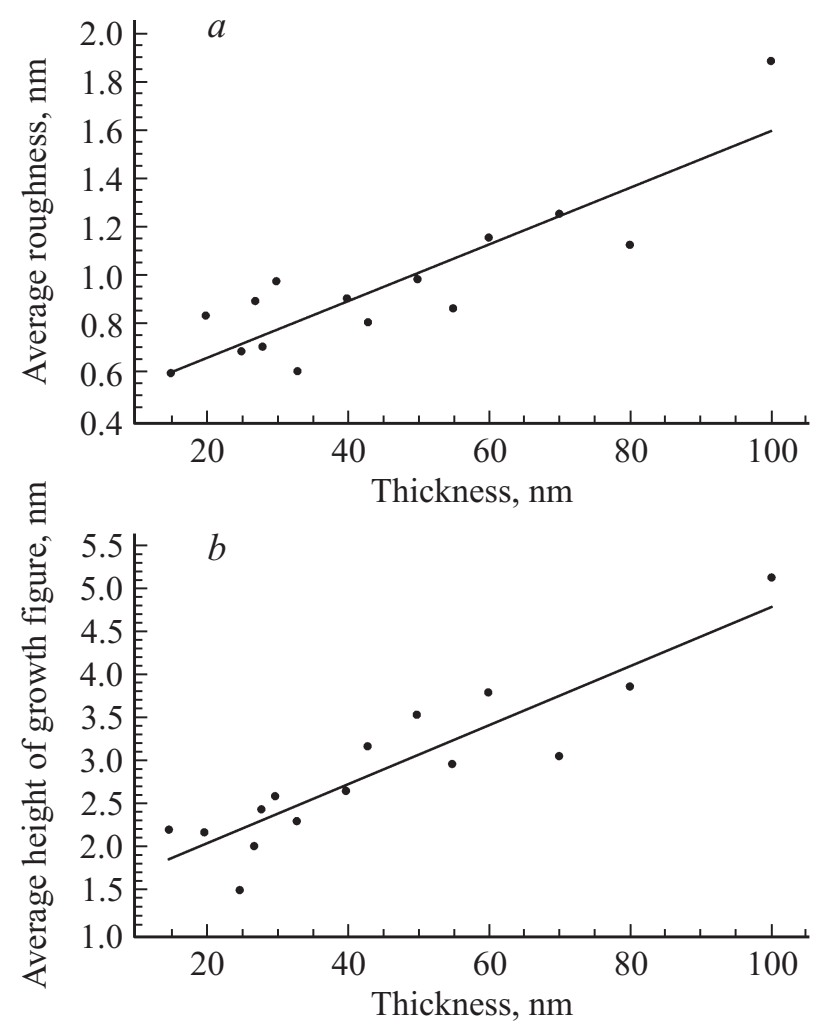

Рис. 2. Зависимости от толщины пленки: $a-$ средней шероховатости поверхности; $b-$ средней высоты фигур роста.

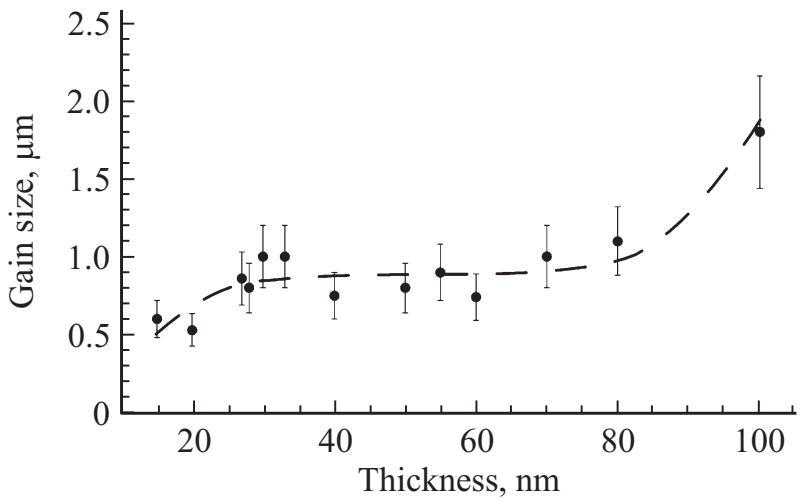

Рис. 3. Зависимость размера кристаллитов ультратонких пленок висмута от толщины пленки.

существенно - для пленок толщинами меньше 40 нм отношение средней высоты фигуры роста над основанием к толщине пленки составляет величину $\sim 10-15 \%$ и слабо зависит от толщины.

Данное значение, вообще говоря, велико и говорит об увеличении вклада поверхности в формирование общей кристаллической структуры пленки. Поэтому при изучении пленок толщинами меньше 40 нм можно ожидать проявлений этого влияния, например, на явления переноса электрического заряда.

Для пленок различной толщины методом АСМ были получены данные о зависимости среднего размера кристаллитов от толщины пленки, которые представлены на рис. 3. Видно, что размер кристаллита мало зависит от толщины в интервале толщин $27-70$ нм и увеличивается при толщине пленки $15 \leq t \leq 27$ нм и $70 \leq t \leq 100$ нм.

Отметим, что средний размер кристаллитов в исследованных пленках превосходит толщину пленки, как минимум, на порядок. Как показано в работах $[1,2]$, при выполнении подобного требования (при данных условиях получения образцов) можно утверждать, что кристаллиты проникают в глубь пленки на всю ее толщину (особенно при столь малых толщинах), и, следовательно, становится возможным судить о внутренней структуре пленки по морфологии ее поверхности.

\section{4. Заключение}

На основании приведенных результатов исследования можно сделать следующие выводы.

1. При получении пленок висмута методом термического испарения в вакууме $10^{-8}$ мм рт.ст. на скоростях осаждения $1.5 \AA / \mathrm{c}$ на слюдяную подложку при температуре последней выше $100^{\circ} \mathrm{C}$ поверхность полученных пленок обладает следующими особенностями: фигуры роста треугольной формы имеют пирамидальную конфигурацию, а также совместно с хиллоками имеют хорошо выраженную огранку. Данный факт свидетельствует о 
протекании процесса получения пленки в условиях, близких к термодинамическому равновесию.

2. Установлен близкий к линейному характер зависимостей средней шероховатости поверхности и средней высоты фигуры роста от толщины пленки. При этом для пленок толщинами меньше 40 нм отношение средней высоты фигур роста над основанием к толщине пленки составляет величину 10-15\%.

3. Обнаружено увеличение среднего размера кристаллитов с увеличением толщины пленки. Выявлена слабая зависимость размера кристаллита от толщины при толщинах 27-70 нм со средним значением размера кристаллитов в этой области $\sim 0.8$ мкм.

Полученные результаты в настоящее время используются при интерпретации эффектов в гальваномагнитных и термоэлектрических явлениях, наблюдаемых на температурных, магнитополевых и толщинных зависимостях кинетических коэффициентов носителей заряда в ультратонких пленках висмута на слюде.

Работа выполнена при финансовой поддержке Министерства образования и науки России в рамках государственного задания на выполнение государственных работ в сфере научной деятельности.

\section{Список литературы}

[1] В.М. Грабов, Е.В. Демидов, В.А. Комаров. ФТТ, 50 (7), $1312(2008)$.

[2] В.М. Грабов, Е.В. Демидов, В.А. Комаров, М.М. Климантов. ФТТ, 51 (4), 800 (2009).

[3] M.O. Boffoué, B. Lenoir, A. Jacquot, H. Scherrer, A. Dauscher, M. Stölzer. J. Phys. Chem. Sol., 61 (12), 1979 (2000).

[4] X. Duan, J. Yang, W. Zhu, X. Fan, C. Xiao. Mater. Lett., 61 (22), 4341 (2007).

[5] L. Kumari, S.-J. Lin, J.-H. Lin, Y.-R. Ma, P.-C. Lee, Y. Liou. Appl. Surf. Sci., 253 (14), 5931 (2007).

[6] N. Marcano, S. Sangiao, C. Magén, L. Morellón, M.R. Ibarra, M. Plaza, L. Pérez, J.M. De Teresa. Phys. Rev. B, 82 (12), 12532 (2010).

[7] E.I. Rogacheva, S.N. Grigorov, O.N. Nashchekina, S. Lyubchenko, M.S. Dresselhaus. Appl. Phys. Lett., 82 (16), 2628 (2003).

[8] Е.В. Демидов. Автореф. канд. дис. (СПб., РГПУ им. А.И. Герцена, 2009).

[9] A. Zangwill. Amer. J. Phys., 56 (12), 1155 (1988).

[10] T.E. Madey, C.H. Nien, K. Pelhos, J.J. Kolodziej, I.M. Abdelrehim, H.S. Tao. Surf. Sci., 438 (1-3), 191 (1999).

[11] I. Ermanoski, C. Kim, S.P. Kelty, T.E. Madey. Surf. Sci., 596 (1-3), 89 (2005).

Редактор А.Н. Смирнов

\section{The dependence of surface morphology of ultrathin bismuth films onto mica substrate on the film thickness}

\author{
A.N. Krushelnitckii, E.V. Demidov, E.K. Ivanova, \\ N.S. Kablukova, V.A. Komarov
}

The Herzen State Pedagogical University of Russia, 191186 St. Petersburg, Russia

Abstract The results of researching the surface of bismuth films (thickness $15-100 \mathrm{~nm}$ ) on mica substrate by the atomicforce microscopy are presented. Almost linear dependence of the average surface roughness and the average height growth figures from the film thickness is shown. The increase in the average size of crystallites with increasing film thickness is detected and the weak dependence of the crystallite size from the thickness at thicknesses of $27-70 \mathrm{~nm}$ is revealed. 